\title{
- auto camoniano d'el rei seleuco: as poeticas do auto - CAPITULO DE UM ESTUdo INEDITO SOBRE O TEATRO CAMONIANO.
}

\author{
Franclaco Casado Gomea
}

O "Auto d'El-Rei Seleuco" apresenta, como já o sugerira Aristóteles, na sua Poética, a história de um homem "comum", que não se nos impõe por bondade ou maldade, por amor à Justiça ou à perversidade, e - não obstante - cai no infortúnio, em conseqüência de um erro involuntário.

E esta história pode ser real ou fictícia, e, se apresenta nomes próprios, é apenas para inspirar mais confiança, pois a realidade confirma a ficção.

Nesta, a ação de Seleuco, a cedência da própria esposa ao fiIho, tem algo de tragédia. Equivale a um suicídio, a um matar-se para a vida do amor, que é tão valorizada por aqueles que o levam, homicidamente, a essa resolução heróica.

Com isto, pretende sugerir terror diante do acontecido, e compaixão por quem o sofre, principalmente porque tudo ocorre, sem maldade, entre amigos-parentes tão próximos.

O pai estava, sem o saber e sem o querer, a matar o filho. Mas, ao tomar conhecimento do fato, prefere morrer para salvar o filho, que desejava morrer para não o ofender.

Estes dois caracteres, bem como a Rainha, têm boa qualidade, conformidade e coerência, ao longo de toda a peça, portando-se com verossimilhança nos diálogos e na in/ação.

As cenas estão bem entrosadas e, em conjunto, fazem do Auto uma peça de ação complexa, pais a "mudança de fortuna" resulta da peripécia e do (re)conhecimento da verdade.

E de lembrar que, para certos espectadores, pode parecer que - Auto desrespeita algumas conveniências externas. Mas os "reconhecimentos" da verdade ocorrem por: exteriorização do psíquico através do físico (palidez e lágrimas por tristeza, e alteração do pulso por emoção), objeto (o papel apanhado por Prolalta) e silo- 
gismo (o usado pelo Físico, na cena 11).

Ainda em obediência às lições de Aristóteles, o "nó" abrange os atos 1 e 3 . Aliás, é na cena 10 , já no $4 .^{\circ}$ ato, que ocorre o fim do periodo que pode ser tido como "antes", e se desencadeia o "depois", já que se invertem os sinais das vivências do Rei e do Príncipe. E é no $4 .^{\circ}$ ato que se dá o "desenlace"; o $5^{\circ}$ é uma espécie de "estásimo". O "párodo" já ocorre na cena 9, ao clausurarse o nó.

O solilóquio de Seleuco na cena $18\left(5 .^{\circ}\right.$ ato $)$ é quase um "párodo", porque é a justificativa do "suicidio" e a justificação dos agozes que pecaram por amor.

A resolução do Rei, tomada após a agnórise desencadeada pela cilada do Fisico, que é uma verdadeira "peripécia", tem muito de patético.

No Auto há epicurismo e estoicismo diante da vida e do amor, e este é tido como potência sobre/-natural que domina o homem, e fá-lo viver um sentimento de culpa.

Em Seleuco há o destemor das ações, uma espécie de epicurismo, pois, ao comprar Estratônica e ao cedê-la ao filho, age por inreresse pessoal e em desrespeito a um de dois códigos, mas justamente por isto - acata um aspecto do estoicismo, respeitando a ordem que the parece razoável e natural.

Antíco é puramente estóico, no sentido de submeter-se ds determinações do Destino, sem forças para reagir, e dai decorre sua obediência à ordem paterna de passar a viver em desrespeito ao código que aceitava.

Antíoco é puramente estóico, no sentido de submeter-se às determinaçōes do Destino, sem forças para reagir, e dai decorre sua obediência à ordem paterna de passar a viver em desrespeito ao código que aceitava.

A idéia de harmonizar opostos, decorrente do epicurismo, é um dos aspectos da "disciplina" clássica, a harmonia, a "si(n)metria" da forma que foi buscada e obtida no equilíbrio quantitativo, como o provamos.

Mas, se a "forma da expressão" aproveitou a essência do Classicismo, a "forma do conteúdo" obedeceu à vivência epocal, mareirista.

A forma da expressão, o artifício, o artesanato, que possibilita 
a realização pessoal da "poesia pura", é fruto da idéia, do pensamento $e$, por isto, atemporal e inespacial, e serve de base expressiva para uma arte engajada, isto é: com finalidade de crítica social, de comunicaçãa re/construtiva.

Aliás, a temática também obedece a, uma "si(n)metria" e valoriza os possíveis enfoques críticos, pondo em relevo a angústia existencial, determinada pelo entrechoque dos códigos, vivido no e como Maneirismo.

O teste da expressāo relaciona-se com o da comunicação denunciadora, pois nos dois é necessário ler nas entrelinhas.

O Autor quis dar ordem e harmonia ao Caos, conforme a lição de Aristóteles, para quem "a arte consistiria na criação de um mundo coeso, paraielo ao Cosmos" e a obra dá recriação estaria para a obra da criação como o poeta - estaria para o demiurgo, ou o criador do Universo" (Moisés - in "A Criação Poética", p. 15. Ed. Melhoramentos. S. Pa,ulo, 1977).

Mas Camões Exigiu "consumidores" capazes de decifrar seus códigos de expressão e de comunicação.

A harmonia quantitativa da expressão é o "logos-discurso" que possibilita a catarse da angústia da in-/comumicação psicossocial e oos desconcertos da vida.

O equilíbrio "métrico" é a doação de plenitude emotiva e esrética dominada pela carência de ordem social, pelo entrechoque do icódigo permissiva, antropocêntrico, renascentista, com o repressivo, teocêntrico e tridentino.

O desejo de conhecer a verdade e a necessidade de fazミr jusliça, apresentados por Seleuco, e o fato de ele julgar que transmitira, por hereditariedade, suas culpas a Antíoco - lembram aspectos da teoria de Esquilo.

O pormenorizado exame das subjetividades e dos enigmas vitais, que aparecem no Auto, recordam questōes que Euripedes já propusera..

A idéia de que a beleza física é espelho da beleza anímica, que ocorre na peça, é pensamento de Castiglione, via Ficcino. Aliás, Este já fálara no "homem saturnino" que tanto se parece com Seleuco, que tenta reparar a involuntária culpa, com uma vo'untária penitência; que recrimina a imprudência e valoriza a razão, vindo a cair numa crise de consciência, mas seu "ethos" sobrepuja o "pa- 
thos" que desencadeará a "praxis".

Seleuco não é apenas mais uma figura da História a aparecer na Literatura. - E um símbolo, uma exemplaridade universalizável, que poda e deve levar à catarse.

Quanto às qualidades da elocução: o Auto apresenta-se com espontaneidade e clareza, mediante um léxico coloquial e com poucas e pequenas desobediências à sintaxe normal, e sem cair em trivialidades.

Percebe-se ter havido a preocupação em provar que a beleza de um todo deve ser visivel pela ordem e equilibrio de suas partes, e que essa harmônica simetria é qualitativa e quantitativamente oistribuída, nos atos, cenas, falas e esquemas rimáticos.

E chega a haver marcação especial para os casos "dinos de memória", mediante o uso de estrofes heterométricas, de versos heterofônicos ou de pé-quebrado, e assim faz a correlação en're o pensamento e a elocuçāo.

$$
x \quad x
$$

Há neste Auto algumas passagens que podem lembrar o "código do vinho" aceito por Horácio ${ }^{1}$ ).

Seleuco, "homem velho, cansado", imprudentemente segue a natureza, cometendo o excesso de casar com uma jovem e disto resulta uma série de casos nefastos.

Seleuco, sem que tivesse bebido, sente-se "emeninecer", estar "mudado", alegre, feliz, como se por influência de vinho, por estar casado com Estratônica, e bem aproveitando seus dias.

Mas o jovem Antioco, que "ama desesperado", deseja a morte como solução de seu problema e o mesmo acontece à Rainha, tendo ambos - portanto - sobeja razão de beber, mas não o fazem.

O código repressivo, que lhes impede a união, é citadino, e acatado numa corte em que o convívio é superficial, inautêntico, pois os jovens escondem seus verdadeiros sentimentos. Não sacrificam aos deuses mas se auto-imolam por causa do daver, não permitindo que a razão sucumba à força da paixão.

O auto canta as coitas do amor e não a guerra, reconhece o valor do amor paterno e, se apresenta uma afeição impossivel, faz com que os que a sentem não à realizem indecorosamente.

Horácio colocava sua lira a serviço do Império. Seleuco muito 
se preocupa com o Reino e a ele sacrifica seus direitos de marido e faz sacrifícios propiciatórios aos deuses.

Antioco descrê da ciência médica e vive em função de seus sentimentos. Estratônica mais sente do que vê.

No Auto há a regra das estações, pois ao inverno, o tempo de Seleuco, sucede a primavera, a época de Antioco. O primeiro é homem dado ao "nsgotium", é um mercantilista, ao passo que o filho vive no "otium" nefasto de um amor impossivel, e passa deitado horas a fio, como à espera da morte, da qual é salvo pelo pai, que - ressuscita para a vida no amor, em companhia de Estratônica e na presença de bem escolhidos criados.

O paço real, que fora o locus horrendus para os jovens, passa a locus amoenus, onde viverão um amor conseñtido pela comunidade, e é por isto que Seleuco ordena: "hajam festas de prazer" (...). "Hajam cantos pera ouvir,/jogos, prazeres sem fundo", uma verdadeira comemoração, uma espécie de festim horaciano, financiado por alguém que, por seguir a razão e viver o amor paterno, não se revolta contra o filho e a própria esposa, cujo amor fora descoberto pelo físico, um pequeno burguês assalariado que. por dever, torna-se o aliado da triade aristocrata.

"O Auto d'El-Rei Seleuco" lembra-nos páginas do "Cancioneiro Geral", organizado por Garcia de Resende, que valcrizou a mesura medieval e a coita d'amor, ao registrar o processo do "Cuidar e Suspirar", semelhante ao vivido por Antísco.

Naqusla antologia, como no Auto, faz-se análise psicológica com subtilezas dialéticas, e dá-se maior atenção à introspeeção do que à descrição de ambientes.

$\mathrm{Na}$ Auto porém, só há meditação social e não narrativas de sociabilidade que ocorrem no Cancioneiro, mas em ambos os livros lê-se a crônica sentida de mal-maridadas, como Estratônica, que teve a coragem de, na luta entre o ideal e a realidade, desejar viver um amor natural e pleno com seu poeta-príncipe-servidor, disposto a morrer por amor mas também desejoso de viver para amar a sua "bem talhada señor", que deveria ser inacessível, conforme a ordem lítero-social vigente.

No Auto, como no Cancioneiro Geral, através da redondilha maior, estrofada em falsas-décimas, fala-se em um sonho ミrótico, de amargo despertar, e na impotência ou esterilidade de um velho. 
Nas duas obras há bilingüismos, mas também galhofa contra espanhóis, crítica a maus clérigos e a judeus, e provas de que, no $\mathrm{Pa}$ ço, havia pacífica convivencia entre aristocratas e populares, e todos a falar, com limitado vocabulário, sobre a vida de epicuristos, apesar dos desconcertos do mundo, que bem se coadunavam com a propositada cacofonia de certos versos.

"As Trovas à morte de D. Inês de Castro" mostram que o código sócio-moral de Resende era bem semelhante ao permissivo, que presidiu e justificou a atitude de Seleuco, que reconheceu a inocência de Estratônica "por [ela] ter muito fervente / lealdade, fé, amor, / do príncipe [seu] senhor, como tivera Inês".

Ambas as mulheres, por e para sua desventura, foram postas em "tanta altura", e ambas "de tal doutrina [ e virtudes qu'era(m) dina(s) de (seu) mal ser ao revés", pois o crime delas fora, querer bem quem as queria, e ambas quiseram a liberdade de amar sem sentir a perda da fama.

Aliás, a solução do drama dos jovens amadores do Auto í́ fora defendida, no Cancioneiro Geral, por Aires Teles.

Mas, este antropocentrismo permissivo que, no Auto, tão bem valorizou o reconhecimento aristotélico graças ao aproveitamento do experimentalismo científico do Físico, e que registra com simpatia as doridas confissōes de amor impossivel, é expresso através do aproveitamento de uma "fábula clássica".

E na nova versão as personagens sen / tem e defendem a liberdade... de errar, apesar da Razão - porque mal informada pelos sentidos e/ou pela paixäo.

Este grave problema da responsabilidade pessoal e social 6 apresentado por vivências naturais mas imprudentes, se bem que verossimeis.

O Auto camoniano é "humanista" na medida em que o honiem-amador é o centro do mundo, o seu único e real interesse. $E$ a não localização, no tempo e no espaço, das personagens símbolos, bem indica o desejo de generalizar, de universalizar os enfoques a o drama.

Tem, ainda, do humanismo - a preocupação com a função social da literatura, que, porém, não deve ser moralista.

O Auto, apesar de haver sido escrito e encenado antes de que a "lei das unidades" começasse a prevalecer, respeita-as. Há uma 
Só entriga, à qual se prende uma secundária, colocada à parte, em um ato independente. As vivencias poderiam ocorrer em apenas vinte-e-quatro horas e se passam em uma única sala, se bem que dividida em dois ambientes.

As conveniências internas obedecem à lição aristotélica, mas as exlernas retratam vivências da época do Maneirismo, como passamos a demonstrar.

Ao equilíbrio e a proporção, desejados e obtidos na forma, 0 A.utor opõe o desequilibrio, a desordミm e a insegurança psíquicas, vivenciadas pelas personagens, justamente por causa do choque entre Natureza e Cultura.

A essência da humanidade do Auto não é o-ver nem o saber, mas o apalpar e sentir, não é a ação impensada mas a inação ou reação por inércia; não é o olimismo em face às possibilidades do indivíduo, mas o pessimismo diante da intolerável des/-ordem grupal.

O homem é dominado pela força sobre/-natural do Amor, e esta nāo é lógica. nem "humana". A verdade vista pode ser mentira; a realidade sentida, inexistente. A inverdade afirmada pode ser uma realidade verdadeira, e a moral do Estado pode e deve prevalecer sobre a moralidade pessoal.

As personagens sentem, em si mesmas, a luta entre a razãoordem epocal e 0 desejo-instinto permanente. Sofrem as consequiências da guerra entre corpo e alma, entre o querer e o dever; entre - viver e ser feliz.

- Amor ora se thes impõe como paixão individual e egoista, oro, como sentimento sócio-moral e altruista. Liberta e aprisiona; domina e transcendentaliza. Suscita uma constante tensão e quer a concórdia dos inconciliáveis.

Há, no Auto, a valorização de um caso estranho e extremo, a que foi dada uma solução imediatista, e provocadora de debates, já que é contrária ao "bom senso" marital individualista e vaidoso, mas que é conforme o amor paternal e à razão de Estado.

Solução problematizante, enfatizadora de ambivalências, fruto e causa de tensōes simultâneas e irreconciliáveis; ótima ou péssina, conforme o julgador des/-interessado.

As personagens sentem que a vida é complexa e paradoxal, 
mas apetecivel, e que - por isso mesmo - a siiuação é de "humour".

Já que a existência é inexplicável racionalmente, e até mesmo não o é apenas pelo instinto - o melhor é não tentar explicá-la; é viver sem pensar - mas isto pode merecer castigos, como - aliás - ocorreu a Seleuco.

A religiosidade dele, imanente e mercantilista, mais fruto do sentimento de culpa e do interesse pelo filho do que amor aos deuses, tenta apenas melhorar o seu mundo e não dele transcender.

No Auto temos uma estrutura que parece inorganizada mas que, bem observada, mostra organicidade e equilíbrio, e isto sugere um exame atento das realidades, através dos sentidos, apesar de estes poderem enganar, desencadeando novas tensões e novos questionamentos.

E preciso confiar desconfiando da validade das observações, já que estas não podem abarcar, simultaneamente, todo o "voiúme" das realidades. Sempre haverá face(s) oculta(s), e não podemos traçar limites exatos entre ser e parecer.

O Auto procura provar a des-/vantagem da introspecção, da busca por conhecer os próprios sentimentos e conviç̧ões, já que tal saber pode causar in./felicidade.

A peça nasce de uma outra obra de arte e não da dire:a observação de um fato real, mas dá nova interpretação à ve!ha fábula.

Há, no Auto, o relato de um sonho erótico, tido sem o controle do código repressivo, mas esta flutuação entre aparência. e realidade desaparece, para dar ocasiäo à dura verdade: tudo é sombra, mentira e desengano, ao acordar.

O realtivismo psicológico e moral é a base da crítica social no Auto, já que a simplicidade e a espontaneidade seriam antinaturais raquela época de refinamento psíquico e social, ditado pela escritura do tempo.

Observa-se haver clara preferência pelas vivências intelectuais, controladas por ideologias, e o enredo do Auto valoriza aspectos psicológico-morais com o fito de inquietar, de conscientizar o auditório.

Examina problemas sem lhes dar verdadeiras e permanentes soluções, já que o sistema de interpretação dos fátos não é cêntri- 
co mas elíptico, pois se aproxima e afasta da solução, sem a atingir.

No "sistema solar" do Auto poder-se-á ver uma espécie de heliocentrismo, no qual o Rei-terra e a Rainha-lua giram ao redor do Príncipe-sol?

Ou a, aceitação do "geocentrismo"? Ou - ainda, uma dúvida científica? já que as rotações passam, alternadamente, por dois pólos, realçando a relatividade dos valores, num mundo em que tuco é in-/justo e in-/oportuno, dependendo apenas do ponto de vista do(s) observador(es) e da instável situação psico-morál dele(s).

A relatividade da Moral(idade) do Auto estó a sugerir a aceitação de uma Moral antropocêntrica, casuística?

Reconhece que a Razão é influenciável por forças externas ocacionais, e que a axiologia se submete à práxis?

Parece sugerir que o homem só se conhece quando um outro - sofre, e que esta auto-ignoråncia é a causa de inquietaçăo e frustraçz̃o, e que - na irresponsabilidade da imprevidência é responsável, e que deve ser providente diante de outros.

Mas, não sabe se tem, ou não, o direito de ser ou de fazer, já que pode estar a ofender direitos alheios. Até o querer ser bom e justo para consigo ou para com outrem pode causar injustiças e malfeitorias a terceiro(s).

Qualquer auto-afirmação pode gerar antagonismos indesejados, e de difficil solução. Mas, como viver sem atuar? Dál a angústia existencial.

O Auto parece querer obrigar-nos a perguntar: valerá a pena acatar uma ideologia, um código cultural repressivo, contrário aos naturais anseios, e - por isso mesmo - antinatural?

Mas, um código permissivo nunce será contra alguém?

Qual a ordem social que sempre estarb́ a favor de todos?

Temos, neste mundo, um cosmos ou um caos?

Quando o homem deixará de ser personagem problematizada e problematizante?

$$
x \quad x
$$

O fato de Seleuco comprar Estratónica e de tentar adquirir a mulher do Físico, para ser feliz, e para recobrar a saúde do Prín- 
cipe, s5o atitudes ilícitas e sintomas da mentalidade capitalista epocal, já que reificadorás do homem, mas ditadas por "bons" instıntos, e estes, porém, a valer-se do valor-dinheiro que reduz todos e tudo a um denominador comum, objetivo, impessoal, antihumano.

Apesar da. mentalidade capitalista de Seleuco, e justamente porque o Auto a critica, não aparece o choque sócio-económico entre patröes e criados, a não ser na cena $4 .^{\circ}$.

O egoísmo atuante de Seleuco, como indivíduo e como pai, gera - para ele e nele - a solidão culpada, a incomunicabilidade entre ele e seus beneficiários, apesar de seu sacrifício. Aliós, a atitude deles, dos jovens amadores, também é egoistica.

Seleuco sente-se mais esposo e pai do que rei, mas é graças ao fato de reinar que pode resolver os problemas que criara para o filho e para a esposa.

O herói, que dá nome ao Auto, passa a viver na solidāo, apesar de estar numa comunidade da qual é o chefe, e que foi, nova. mente, por ele organizada.

A sua atuação, abnegada penitência e altruísmo, volta-se contra ele, mas é graças a ela que terá a tranqüilidade do dever cumprido, e bem justificado.

Aliás, explica e perdoa a atitude da Rainha, e isto poderó ser um mérito moral, causa de admiração dos convivas e entre eles est6 o Porteiro, que viveu antecipadamente o drama do Rei, que põe em relevo os suas atitudes antagônicas, determinadas por causas externas (a beleza da mulher e a doença do filho), e em cujo passado houve uma imprudência que deve ser purgada no futuro.

Mas esta regra aceita exceção, pois a Rainha, sua conivente no crime de uma união absurda, bem pouco sofre, e tem a juventude e o futuro a seu favor.

As contradiçōes psicológicas, a des-/esperança por causa da i-/legitimidade do amor sāo tentativas de realçar os caracteres problematizados, naquela sociedade alienada e desconcertante.

Aliás, Estratônica vive à margem de sua própria realidade interior, sem confessar nem a si mesma o crime-pecado que está a cometer, até que Frolaita a violenta com a presença do papel escrito pelo Príncipe. 
Seleuco, ao buscar o prazer do convívio marital com a jovem, encontra o desprazer, a culpa, a penitência, e o seu lar transformase em "locus horrendus" para ele, e talvez também para os moços.

A autovitória do Rei é psíquica e moral, mas também uma derrota, ético-social.

O Auto é um drama de destino, no qual é intensa e continuada a interiorização expressa nos solilóquios e em alguns diólogos, num dos quais Seleuco reconhece ser a causa eficiente de seu prófrio drama, e, por isto, a peça não pode ser tida como tragédia "antiga".

O drama deles, principalmente o do Rei, é determinado por ação pessoal, anterior, imprudente mas aceitável pelo grupo, se bem que contrariada pela in-/justa onipotência dó Amor, qu o condena a viver perigosamente a liberdade de poder acertar ou errar ao tomar decisões.

Há também a punição da ir-/responsabilidade de culpados-inocentes, para os quais o castigo é prêmio, e estas vítimas-heróis não são maiores nem menores do que suas próprias ações, mui humanas, espontâneas, justificáveis.

Há uma atitude de "humour" diante da alienação e da ambivalência da sociedade, no fato de a Rainha ter esperança, na desesFerança, de alcançar o impossível, e por isto não se vê tragicidade na peça.

Aceita-se a infelicidade como algo inerente ao destino humano, mas se procura remediar a situação graças a liberdade atuante e responsável, mesmo que para tanto se deseje fugir do mundo desconcertado, por meio da morte, castigo-prêmio.

A piedade, a compreensão, o respeito ao homem, a tolerância equilibram o ridículo e o sublime das situações, e assim se evita(m) a revolta contra alguém e/ou o desespero diante do destino.

A inércia de Antíoco e sua constante autolamentação se coadunam com a "apagada e vil tristeza" de sua época de crise. Ele é um vivo-morto à espera, de uma ressurreição, que afinal the é proporcionada. E um astênico mas não abúlico, ao passo que, em Seleuco, há algo de maneirismo quixotesco o acendrado amor paternal e o acrisolado patriotismo, que o levam a fazer extremos, exemplos da contradição entre o ideal e a realidade.

E no Auto foi fácil apresentar o ideal cortês, a elegância, a 
mesura, a subtileza áulicas - por ser uma história vivida num paço real, aliás uma côrte muito simples e com poucos cortesãos, quase todos servidores do Amor, e muitos deles bons conhecedores dos desconcertos do mundo, criados pelo amor... sem transcendências ascético-místicas.

A peça estuda e realça um valor autêntico, o "amor verdadeiro", num mundo degradado felo mercantilismo e pelo hedonismo, geradores do drama animico e social que apresen.a.

O Rei e a Rainha vivem, inicialmente, uma mentalidade burguesa, atribuindo ao dinheiro e ao presígio social vaiores absolutos. Mas o Príncipe vive e defende valor diverso, que, afinal, é reconhec'do e respeitado pelos outros - o amor "natural", que paira acima de tudo, mas para cuja satisfação é imprescindivel a liceidade, reconhecida peia legítima autoridade.

E por isto que há a reconciliaçāo dos jovens com a comunidade, que deve festejá-los, mas eles não se comunicam com o grupo, pois são seres à parte, já que vivendo um amor verdadeiro.

$$
x \times x
$$

Quanto ao aspecto formal, o Auto muito pouco tem de acumulação de símiles, de metaforismos, de jogos de palavras ou de agucos conceitos. Não pretende "stupire", mas quer fazer pensar sobre os paradoxos e contradições insuperáveis propostos pela vida, e não pelo enunciado, que conta uma fábula vercssímil de modo a ser entendida por todos, e não só por iniciados.

Todos podem sentir a antítese existencial das personagens, sem que se recorra à antítese verbal dos conceitos.

O Auto em questão organiza-se graças à exteriorização verbal, pensada, de emoçōes vividas por vários falantes-narradores, e cada um deles tem seu próprio "estilo", graças a capacidade de o Autor sentir e falar por muitos, o que the fossibilita melhor analise de suas próprias vivências.

E se a Poesia é tensão, conflito, antinomia e ambivalência, pode afirmar-se que este Auto é realmente poético ao falar-nos da luta do(s) indivíduo(s) contra o Destino, do homem contra a. Sociedade, da Natureza contra a Cultura, do desejo de paz e segurança ao chocar-se com a insegurança e o desconcerto.

Neste Auto, o "poeta da emoçāo" sobrspuja o "poeta do pensamento", e a preocupação com o equilibrio quantitativo comprova 
a vontade de o Autor, mostrar-se como "poeta esteta", lírico, mas sem prejuízo de um posicionamento crítico diante da vida.

$x \quad x$

Dentro da "originalidade da literatura portuguesa"(1) este Auto é um fruto sazonado da, cultura de várias épocas, e deu relevo ao gênio amoroso, triste, desesperançado do português e também mostra ser necessário o esforço de uma elite para "modernizar" a Nação, na qual - como na peça em foco - "os sentidos (...) são redimidos e sublimados pela, própria elevação (...) do ideal e do sonho" e onde se faz "uma (quase) identificação do amor com o sofrimento", mas sem tragédia, mansa e fatalisticamente, com pouca ação e muita lágrima.

Sr. José Luiz da V. Mercer

Francisco Casado Gomes foi titular (catedrático por concurso) de Literatura Portuguesa na U.F. RGS, da qual está aposentado (1980). Fundou o Gabinete Português de Leitura e os Centros de Estudos Portugueses nas Universidades: Federal do RS, Federal de Santa Maria, Federal de Pelotas, Católica de Pelotas e na de Caxias do Sul. Publicou, como diretor, 21 números do Boletim do Gabinete Português de Leitura, e os seguintes livros: Dicionário de Termos Gramaticais e Dicionário das Literaturas Portuguesa e Brasileira (secções da $10^{\circ}$ ed. da Enciclopédia do Curso Secundário - Globo 1940); Camoniana (Ed. Instituto Estadual do Livro, 1958); LEmbranças e impressōes de Leituras (Ed. Emma; 1959); O mar na obra, de Antônio Nobre (tese de concurso, 1958). Tem em andamento um estudo sobre o teatro camoniano, que ocupará seis volumes, três dos quais preparados por computação eletrônica, usando um método pessoal.

\section{RES U M O}

Observa-se a influência da "Poética" de Aristóteles neste Auto que é um drama de destino, e em que se vê epicurismo, estoicismo e mercantilismo no decorrer da narrativa expressa em forma "clássica", graças ao equilíbrio quantitativo de suas duas grande-seqüências e dos seus cinco atos opositivos mas resolutivos, nos quais se tenta resolver os problemas criados pelo código epocal, de fundo maneirista.

Hó também reminiscências de Ésquilo, Eurípedes, Horácio, Castiglione e de autores do Cancioneiro Geral, de Garcia de Resende, e dos teatros de Gil Vicente e Sá de Miranda. 
A peça não apresenta, a euforia humanista mas tem o homem (amador) como seu principal interesse.

No Auto há apenas uma função cardinal, que se repete: vir e esta determina algumas poucas cenas subordinantes, ao lado das quais aparecem outras coordenadas e equipolentes, em que há 254 linhas das oito cenas em prosa e a parte das "figuras de siso" (dezoito cenas) ocupa 731 versos, distribuidos em quintilhas (127), sextilhas (6), tercetos (3), quadras (2) décima (1), uma estrofe de doze versos e 3 versos soltos.

Ao longo da peça, tanto na parte em prosa como na em verso, pode levantar-se uma longa série de equilibrios quantitativos, ao nível de: cenas, falantes, e falas por ato; de falantes e interlocutores. Há ainda equilíbrio quantitativo no número de cenas em que falantes intervêm e na quantidade de vezes que usam determinaco(s) esquema(s) rimático(s) nas quintilhas.

Muitas cenas relacionadas, quando somadas, apresentam o mesmo número de versos.

\section{S U M M A R Y}

One can notice the influence of Aristotle's Poetics on this play ("Auto"), a destiny drama, in which one sees Epicureanism, stoicism and mercantilism throughout the narrative expressed in the "classical" form, due to the quantitative equilibrium of its two grand sequences and to its five opposite but resolutive acts, in which one tries to solve the problems created by the Mannerism influenced epochal code.

There are also recollections of Aeschylus, Euripedes, Horatio, Castiglione and the authors of the Cancioneiro Geral, of Garcia de Resende and Gil Vicente and Sá de Miranda's plays.

The play does not present the humanistic euphoria but it has man (the lover) as its chief concern.

There is only one cardinal function that repeats itself in the play ("Auto'): come-go, and this determines some few subordinating scenes, alongside which other coordinated and equipollent scenes appear; there are 254 lines in the eight prose scenes, and the part of the "figures in earnest" ("figuras de sino" - eighteen scenes) has 731 verses, distributed in stanzas of five verses (127), stanzas of six verses (6), triplets (3), quartets (2), stanza of ten verses (1), a stanza of twelve verses an three loose verses. 
Throughout the play, both in its prose and in its verse parts, one can find a long series of quantitative equilibria, namely: scenes, speakers, speeches per act; and a balance of speakers and interlocutors. There is still a quantitative ablance in the number of scenes where the speakers intervene and in the frequency which certain rhyme scheme(s) are used in the stanzas of five verses.

Many related scenes, when added up, present the same number of verses.

] ARIStóteles. Poética. Porto Alegre, Globo, 1966. 264 p.

2 CAMOES, Luis de. Auto del Rei Seleuco. In: ——. Obras complotas. Lisbos, Sá da Costa, 1956. v. 3, p. 77-127.

3 MOISES, M. A criação literária. São Paulo, Melhoramentos, 1977, 881 p.

1 RESENDE, Garcia de. Cancioneiro gerel. Nova ed. Coimbra, Impr. da Universidade, 1910. 8 v. 